Illinois State University

ISU ReD: Research and eData

Theses and Dissertations

7-9-2014

\title{
The Effects Of Cognitively Engaging Physical Activity On The Executive Function Of Sixth Graders
}

Alyssa Michele Humphreys

Illinois State University, amhump2@ilstu.edu

Follow this and additional works at: https://ir.library.illinoisstate.edu/etd

Part of the Kinesiology Commons, and the Neuroscience and Neurobiology Commons

\section{Recommended Citation}

Humphreys, Alyssa Michele, "The Effects Of Cognitively Engaging Physical Activity On The Executive Function Of Sixth Graders" (2014). Theses and Dissertations. 218.

https://ir.library.illinoisstate.edu/etd/218

This Thesis is brought to you for free and open access by ISU ReD: Research and eData. It has been accepted for inclusion in Theses and Dissertations by an authorized administrator of ISU ReD: Research and eData. For more information, please contact ISUReD@ilstu.edu. 


\title{
THE EFFECTS OF COGNITIVELY ENGAGING PHYSICAL ACTIVITY ON THE EXECUTIVE FUNCTION OF SIXTH GRADERS
}

\begin{abstract}
Alyssa M. Humphreys
33 Pages

August 2014

This purpose of this study was to examine the effects of cognitively engaging physical activity, aerobic exercise, and resting conditions on the executive function of sixth graders. Four conditions were tested: cognitively engaging physical activity, repetitive aerobic exercise, cognitively engaging rest, and rest. Executive function was measured by pre and post Stroop tests, which is a test of reaction time and inhibition. Results showed no significant differences between conditions in the choice reaction time test, however the cognitively engaging exercise was significantly different from all other conditions on the Stroop test.
\end{abstract}



THE EFFECTS OF COGNITIVELY ENGAGING PHYSICAL ACTIVITY

ON THE EXECUTIVE FUNCTION

OF SIXTH GRADERS

ALYSSA M. HUMPHREYS

A Thesis Submitted in Partial Fulfillment of the Requirements for the Degree of

MASTER OF SCIENCE

School of Kinesiology and Recreation

ILLINOIS STATE UNIVERSITY

2014 


\begin{abstract}
All rights reserved
INFORMATION TO ALL USERS

The quality of this reproduction is dependent upon the quality of the copy submitted.

In the unlikely event that the author did not send a complete manuscript and there are missing pages, these will be noted. Also, if material had to be removed, a note will indicate the deletion.
\end{abstract}

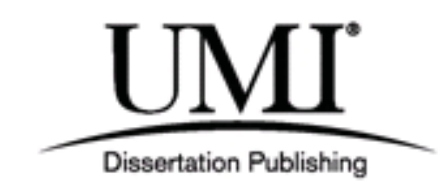

UMI 1568286

Published by ProQuest LLC (2014). Copyright in the Dissertation held by the Author.

Microform Edition (c) ProQuest LLC.

All rights reserved. This work is protected against unauthorized copying under Title 17, United States Code

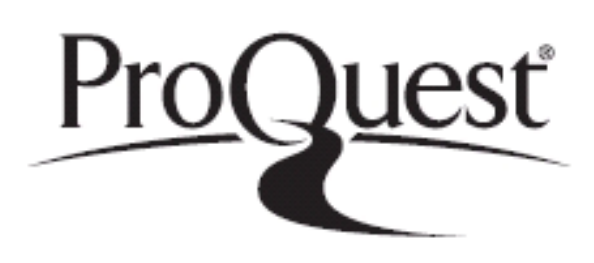

ProQuest LLC.

789 East Eisenhower Parkway

P.O. Box 1346

Ann Arbor, MI 48106 - 1346 
Copyright 2014 Alyssa M. Humphreys 
THE EFFECTS OF COGNITIVELY ENGAGING PHYSICAL ACTIVITY

ON THE EXECUTIVE FUNCTION

OF SIXTH GRADERS

ALYSSA M. HUMPHREYS

COMMITTEE MEMBERS:

Peter Smith, Chair

Anthony Amorose

Kristen Legally 


\section{ACKNOWLEDGMENTS}

I would first like to thank my thesis advisor, Dr. Pete Smith, for working with me on the completion of my thesis. His excitement about the topic of my study was helpful in beginning the process of reviewing the literature. Furthermore, his continued understanding and help during the process of reviewing the literature helped me to grow as a scholar. Throughout the process of preparing for data collection, Pete was very helpful in working out details with Metcalf Laboratory School to use their students as participants in the study. His knowledge of the research process and ability to work through problems along the way taught me the importance of persevering through difficult times. I am truly grateful for the endless amounts of time, emails, and work Pete put in to share his knowledge of research with me.

I would also like to thank other members of my committee, Dr. Tony Amorose and Dr. Kristen Legally. Tony and Kristen were a great help at the beginning of the process and as I delivered my proposal to my committee. They saw the potential in the idea behind my study, and put in a great deal of thought into helping to make my study design the best it could be. I am extremely grateful for the times Kristen was willing to help me search the kinesiology department for heart rate monitors for my study as well as taking the time to explain how to use them. I would also like to acknowledge all of the help I received from Metcalf, including scheduling and the use of their technology and 
space. I would especially like to thank Kim Walker- Smith and Jonathan Haws for their participation in the study. They were both a great deal of help in the planning and execution of a smooth data collection. Kim put in countless hours of work and emails with me to make sure that the day of data collection ran smoothly, and I could not be more grateful for her help. Her organization and knowledge throughout the process was extremely beneficial.

Finally, I would like to thank my family and friends for their endless support through the laughs and the cries. They never hesitated to remind me that although the process was trying, the culmination would be rewarding. I am extremely grateful to Kaitlin McClimon and Gabriela Gonzalez for not only being a great moral support throughout the process, but for helping in the data collection and volunteering their free time to help in any way possible.

A.M.H. 


\section{CONTENTS}

Page

ACKNOWLEDGMENTS

CONTENTS

iii

TABLES

CHAPTER

I. THE PROBLEM AND ITS BACKGROUND 1

Statement of the Problem 1

Research Design $\quad 5$

Participants $\quad 5$

Task/Apparatus $\quad 5$

Exercise Conditions 6

Procedures $\quad 7$

Data Analysis $\quad 8$

Data Preparation $\quad 10$

$\begin{array}{ll}\text { Choice Reaction Time } & 10\end{array}$

$\begin{array}{ll}\text { Stroop Test } & 11\end{array}$

Discussion $\quad 11$

Limitations and Future Research $\quad 13$

$\begin{array}{ll}\text { Conclusions } & 15\end{array}$

II. REVIEW OF RELATED LITERATURE 17

$\begin{array}{ll}\text { Psychophysiology of Exercise } & 17\end{array}$

$\begin{array}{ll}\text { Physical Fitness and Cognition } & 19\end{array}$

$\begin{array}{ll}\text { Chronic Physical Activity and Cognition } & 20\end{array}$

Acute Physical Activity and Cognition $\quad 21$

Physical Activity and Executive Function $\quad 22$

Cognitively Engaging Physical Activity 24

$\begin{array}{ll}\text { Summary } & 25\end{array}$

$\begin{array}{ll}\text { REFERENCES } & 27\end{array}$ 
APPENDIX: Data Points by Subject 


\section{TABLES}

Table

1. Means and Standard Deviations
Page 


\title{
CHAPTER I
}

\section{THE PROBLEM AND ITS BACKGROUND}

\author{
Statement of the Problem
}

While there is a growing body of research that consistently shows a positive relationship between physical activity and cognitive health and function, this relationship has yet to be applied to real world situations. Specifically, evidence for this positive association between physical and cognitive activity has yet to be investigated in physical education classes with school aged children. Such an investigation would be especially important given the increasing nationwide focus on standardized testing and academic performance. This emphasis on academics has led to reductions in length and frequency of physical education classes in schools. However, research has shown that reductions in time allotted to physical education classes have not improved academic performance (Shepard \& Trudeau, 2005). More importantly, taking time away from core classes and allotting that time to physical education has shown an increase in academic performance. According to the School Health Programs and Policies Study (SHPPS), only 3.8\% of elementary schools, $7.9 \%$ of middle schools, and $2.1 \%$ of high schools required and provided daily physical education in 2006 (Lee, Burgeson, Fulton, \& Spain, 2007). As defined in the current literature, daily physical education is considered 150 minutes per 
week for elementary schools and 225 minutes per week for middle and high schools. Academic performance includes behavior (conduct and attendance), cognitive skills such as memory and attention, and academic achievement on standardized tests. It is important to describe the positive benefits of physical activity on cognition in youth and further attempt to define which types of physical activity will be best suited to improve aspects of academic performance.

According to the Society of Health and Physical Educators (SHAPE America), the goal of physical education should be to develop physically literate individuals (SHAPE America, 2013). This includes the ability to participate in and value the contributions of physical activity in daily life as well as understanding the benefits and contributions physical activity has to a healthy lifestyle. SHAPE America attempts to further define physical education with several national standards which outline the development of motor skills, learning of concepts, patterns and strategies of movement, development of proper personal and social behavior, and the value of physical activity for several aspects of health. It is argued by SHAPE America that learning these skills through physical education will help individuals develop well-rounded mental, physical, and social abilities. While many of these skills are taught in physical education classes with the goal of being used outside of the classroom as skills for a healthy lifestyle, improved cognition may be one benefit of physical education that can be immediately and directly beneficial during the school day.

Different aspects of physical activity as well as physical fitness have been linked to improved cognition. Studies focusing on children in $3^{\text {rd }}$ through $5^{\text {th }}$ grade have shown 
positive relationships between aspects of physical fitness and academic achievement, including a positive relationship with aerobic capacity and an inverse relationship with BMI (Castelli, Hillman, Buck, \& Erwin, 2007). Academic achievement was further broken down into subject matter and it was found that reading and math were also related to aerobic fitness and BMI.

Various types of experimental designs have also been used to show the effects exercise can have on cognition. Several acute exercise interventions have tested different duration, intensity levels, and mode to determine how to produce systematic changes in physiological function that may lead to changes in cognitive performance (Audiffren, Tomporowski, \& Zagrodnik, 2009; Davranche, Hall, \& McMorris, 2009; Hillman, et al., 2009; Hillman, Snook, \& Jerome, 2003; McNaughten \& Gabbard, 1993; Pontifex, Hillman, Fernhall, Thompson, \& Valentini, 2009). In several studies, time of day had an effect of the facilitation of cognitive performance by exercise. Exercise seemed to have no effect on performance when testing was done in the morning (Tomporowski, Cognitive and Behavioral Responses to Acture Exercise in Youths: A Review, 2003). Furthermore, duration of exercise has been shown to influence performance. Performance was higher following 50 minutes of exercise as compared to 20,30 , or 40 minutes of exercise (Gabbard \& Barton, 1979). Although some studies showed no effects and some showed facilitative effects, none of the differences in durations created debilitating effects (Tomporowski, Cognitive and Behavioral Responses to Acture Exercise in Youths: A Review, 2003). Yet others have shown debiliative effects in relation to different cognitive processes (Tomporowski, 2003). 
One other important aspect of experimental design is in the mode of physical activity. Most studies have looked at repetitive aerobic exercise such as running, walking, or cycling (Audiffren, Tomporowski, \& Zagrodnik, 2009; Lambourne, Audiffren, \& Tomporowski, 2009; Best J. R., 2010). Still, others have looked at resistance and circuit training as well as stretching exercises (Sibley \& Etnier, 2003). Furthermore, the majority of these studies have focused on measuring the effects of physical activity on executive function. Executive function entails three components: shifting, inhibition, and updating of working memory, all of which are manifested in the prefrontal cortex (Best, 2010). The prefrontal cortext is also connected with complex coordination. Although aerobic exercise has been shown to increase blood flow and other neurotransmitters which leads to greater learning effects, the connection between the prefrontal cortex and coordinative exercise may suggest that physical activity requiring complex thinking and contextual interference may have greater benefits than repetitive aerobic exericse (Budde, Voelcker-Rehage, Pietraßyk-Kendziorra, Ribeiro, \& Tidow, 2008). Examples of coordinative exercises can be anything requiring complex thinking or motor control, and strategy and quick thinking.

This study examined the relationship between cognitively engaging physical activity, repetitive aerobic exercise, resting cognitive engagement and rest with executive function in youth. It was hypothesized that cognitively engaging physical activity performed at a moderate intensity would improve executive function compared to control groups participating in repetitive aerobic exercise at the same duration and intensity, a seated rest group, and a rest group performing cognitive tasks. 


\section{Research Design}

It is the intent of this study to examine the relationship between cognitively engaging physical activity and executive function in youth. It consisted of a within subjects design in which participants all completed each of four separate conditions. Order effects were partially controlled for by ensuring that each group completed the conditions in different orders.

\section{Participants}

Participants were recruited from the sixth grade at Metcalf Laboratory School. Of the 48 students in the grade, we received parent consent and child assent from 47 participants.

\section{Task/Apparatus}

To test executive function, participants completed the Stroop Color-Word Test which tests for inhibition (Banich, 2009; Homack \& Riccio, 2004). The Stroop Task is a highly reliable task which is easily administered to children as well as adults (Archibald $\&$ Kerns, 1999). In other studies using the Stroop task, greater aerobic fitness levels were associated with better Stroop performance (Buck, Hillman, \& Castelli, 2008). The Stroop task was administered electronically via iPads. Participants began by entering their participant ID number and reading instructions for the test. Participants then took a "Stroop-Off" test. This test consisted of a stimulus, "\#\#\#\#”, that appeared on the screen in one of three ink colors: red, green, or blue. Participants were asked to tap the color which appeared on the bottom of the screen) that matched the stimuli. Participants 
completed one attempt of the "Stroop- Off" test. Next, participants took a "Stroop-On" test. For this test, participants were presented with a stimulus of one of three words: red, green, or blue. The word was written in green, blue or red which did not necessarily math the word itself. The participants were instructed to choose the color at the bottom of the screen that matched the color of the ink the word is written in. One attempt was considered complete when the participant correctly named the color of the ink five times in a row. If an attempt was failed, they were prompted to start that attempt from the beginning. The participants had 1 practice attempt and 2 scored attempts. Scores were based on time to complete each attempt successfully.

\section{Exercise Conditions}

Each participant completed four conditions which lasted 15 minutes each. The repetitive aerobic exercise condition consisted of walking/jogging around the gym at a moderate intensity. Each child had received training in understanding the Ratings of Perceived Exertion scale as a component of their previous PE curriculum. Children were asked to monitor their own intensity level so that they remained exercising at a moderate intensity based on their RPE scale. Students were specifically asked to keep their RPE at a level between 5 and 7 and it was explained that this included physical activity that cause heavy breathing that could be sustained over a period of time. The cognitively engaging physical activity condition consisted of an active group game. The group game was a game they had played during their regular physical education class that required all students to obtain a moderate intensity heart rate and required cognitive effort for strategy and quick decision making. The cognitively engaging condition consisted of puzzles and 
math games on the iPad while seated. The names of the math games used were AB Math Lite and Flow Free. The participants in the rest group were instructed to lie quietly for 15 minutes.

\section{Procedures}

Researchers made an initial visit to the school where the study was explained to students and informed consent/assent was sent home with students. Before the first testing session, participants were given informed consent to be taken home, signed by parents and returned to their teacher. After informed consent was received, children read and signed the informed assent. Participants were split into groups with whom they completed each condition. Each group consisted of 11 or 12 students. Data collection took place over four days. Each group completed a different condition on each day until all groups had completed each condition. All groups completed the 4 conditions in different orders. Group one completed rest first, cognitively engaging exercise, aerobic exercise, and math last. Group two completed math first, rest, cognitively engaging physical activity, and aerobic exercise last. Group three completed aerobic exercise first, math, rest, and cognitively engaging physical activity last. Finally, group four completed cognitively engaging physical activity first, aerobic exercise, math, and rest last.

Participants arrived each day, checked a listing for which condition they would complete on that day. If they were completing one of the physical activity conditions, students went to the locker room to change into their physical education clothes. If the student was completing a rest condition on that day, they would begin their pre-condition Stroop test. Once all students from a group had completed the pre-condition Stroop test, the 
group was taken to the proper location for that condition. Each condition lasted 15 minutes. For the two physical activity conditions, the students were asked to engage in moderate intensity physical activity based on RPE scale which they had been trained to use during their regular physical education lessons. Immediately after each condition, participants took their post condition Stroop task.

\section{Data Analysis}

The scores for the first and second trial through the Stroop test were averaged together, so that each participant had one pretest and one posttest Stroop score for each of the four conditions. Because the primary interest of the study was the effect of the four conditions on the speed of response in the two elements of the Stroop test (the choice reaction time part and the Stroop test itself), differences between pre- and post-test scores for the choice reaction time and Stroop test components of the test were calculated for each participant at each of the four conditions. This was calculated by subtracting posttest scores from pre-test scores, so that higher positive scores indicated improvement in performance from pre- to post-test. The specific data points for each subject can be found in Appendix A. These difference scores were then compared across conditions using two one-way repeated measures ANOVAs, with 4 levels of the condition factor (rest, math, walk-run, and cognitively engaging exercise). In one of these analyses the difference scores for the choice reaction time element of the Stroop test was the dependent variable, while in the other the difference score for the average score across the two runs through the Stroop test was the dependent variable. To avoid problems with sphericity, Wilk's $\lambda$ was used as the test statistic. An $\alpha$-level of .05 was used in all cases. 
TABLE 1

Means and Standard Deviations

\begin{tabular}{|c|c|c|c|c|c|c|}
\hline \multicolumn{7}{|c|}{ Cognitively Engaging Physical Activity } \\
\hline & CRT & & & Stroop & & \\
\hline & Pre & Post & Diff & Pre & Post & Diff \\
\hline M & 11.57 & 10.88 & 0.69 & 12.71 & 11.71 & 1 \\
\hline SD & 1.26 & 1.24 & 0.97 & 1.5 & 1.17 & 1.13 \\
\hline \multicolumn{7}{|c|}{ Physical Activity } \\
\hline & CRT & & & Stroop & & \\
\hline & Pre & Post & Diff & Pre & Post & Diff \\
\hline M & 10.98 & 10.69 & 0.29 & 12.39 & 12.24 & 0.15 \\
\hline SD & 1.44 & 1.36 & 1.25 & 2.23 & 2.28 & 1.15 \\
\hline \multicolumn{7}{|c|}{ Math } \\
\hline & CRT & & & Stroop & & \\
\hline & Pre & Post & Diff & Pre & Post & Diff \\
\hline M & 10.73 & 10.84 & -0.11 & 12.54 & 12.41 & 0.13 \\
\hline SD & 1.61 & 1.44 & 1.18 & 2.57 & 2.3 & 1.9 \\
\hline \multicolumn{7}{|c|}{ Rest } \\
\hline & CRT & & & Stroop & & \\
\hline & Pre & Post & Diff & Pre & Post & Diff \\
\hline M & 11.11 & 10.9 & 0.21 & 12.42 & 12.28 & 0.14 \\
\hline SD & 1.74 & 1.43 & 1.33 & 2.05 & 1.98 & 1.68 \\
\hline
\end{tabular}




\section{Data Preparation}

Only those participants with complete data sets were considered for analysis. Of the 47 children to participate in the study, only 30 had complete data sets due to students missing class and therefore missing an entire condition. Of these 30 , three had responses in one or more of the conditions that fell more than 3 standard deviations away from the overall mean for that condition. It was considered highly likely that the cause of these outlying scores was not so much the condition itself but rather the participants' inattentiveness while completing the Stroop test. The Stroop test was completed in the company of all other participants, and as such there were numerous times when students had to be reminded to attend to their own test and not disturb others. Despite the best efforts of the five supervisors, not all instances of off-task behavior could be controlled, thus filtering the data to remove such outliers was felt to be a reasonable means of obtaining the best representation of the conditions' true performances. Overall then, 27 of the original 47 participants were included in the data analysis.

\section{Choice Reaction Time}

The ANOVA was not significant, with $\lambda(3,24)=2.31, p>.05$, partial $\eta^{2}=.22$. The cognitively engaging condition $(\mathrm{M}=.69 \mathrm{SD}=.97)$ was not significantly different from the physical activity condition $(\mathrm{M}=.29, \mathrm{SD}=1.25)$, the math condition $(\mathrm{M}=-$ $.11, \mathrm{SD}=1.10)$, or the rest condition $(\mathrm{M}=.21, \mathrm{SD}=1.30)$. The conditions did not significantly alter choice reaction time performance. 


\section{Stroop Test}

The ANOVA was significant, with $\lambda(3,24)=3.38, p<.05$, partial $\eta^{2}=.30$. The cognitively engaging condition $(\mathrm{M}=1.00 \mathrm{SD}=1.12)$ elicited a larger difference score than the physical activity condition $(\mathrm{M}=.15, \mathrm{SD}=1.15)$, the math condition $(\mathrm{M}=.13$, $\mathrm{SD}=1.90)$, or the rest condition $(\mathrm{M}=.14, \mathrm{SD}=1.68)$. The only condition to significantly reduce their Stroop score was the cognitively engaging physical activity condition.

\section{Discussion}

It was hypothesized that cognitively engaging physical activity performed at a moderate intensity would improve executive function compared to control groups participating in repetitive aerobic exercise at the same duration and intensity, a seated rest group, and a rest group performing cognitive tasks. The main hypothesis was supported by the results of the study. The results support much of the current literature. Several studies showed cognitive improvement following physical activity with the greatest improvements occurring at a moderate intensity for durations greater than 30 minutes (Gabbard \& Barton, 1979; Pontifex, Hillman, Fernhall, Thompson, \& Valentini, 2009). Some studies, however, only showed improved cognition during acute aerobic exercise, and measurements returned to normal immediately following exercise (Audiffren, Tomporowski, \& Zagrodnik, 2009; Lambourne, Audiffren, \& Tomporowski, 2009). Sibley \& Etnier (2003) supported the main hypothesis of this study showing that cognitive engagement inherent in the exercise may also play a role in the cognitive improvement that occurs. However, some studies that have compared physical activity 
requiring varying levels of cognitive engagement, have not shown a difference in cognition during or following exercise. Davranche et. Al (2009) placed participants on an exercise bike at a moderate intensity for 20 minutes. During the cycling, participants engaged in both congruent and non-congruent flanker tasks, which would allow them to compare varying levels of cognitive engagement. The flanker task consists of a series of five arrows. The participant must respond by clicking the arrow button that matches the direction of the center stimulus arrow. A congruent trial would consist of all arrows pointing the same way while an incongruent trial would consist of the center arrow point a different direction than the surrounding arrows. The results of this study were not significant, suggesting that the amount of cognitive engagement inherent in the exercise did not play a role in the cognitive improvement following exercise.

In the current study, the Stroop off condition (choice reaction time) did not show any difference between group conditions suggesting that participating in physical activity versus rest did not significantly improve or debilitate the child's ability to quickly respond to a stimulus. This test, however, was simply a reaction time test and was only used in this study to give the students a chance to practice using the Stroop software on the iPad. The main purpose of the study was to examine the effects that cognitivelyengaging versus repetitive physical activity can have on executive function. Consistent with the hypothesis, the cognitively engaging physical activity measurements were the only measurements to be significantly lowered from their pre to posttest Stroop scores. This means that the cognitively engaging physical activity condition was more effective in improving aspects of executive function than the repetitive aerobic exercise or rest 
conditions. Furthermore, the repetitive aerobic activity condition failed to show a difference between pre and post test scores. This suggests that repetitive physical activity was not, in this instance, sufficient to improve executive function. It is also important to note that the resting math group also failed to significantly improve executive function as measured by Stroop test performance. This means that it may not simply be the cognitive engagement that caused the improved performance, but the combination of physical activity with cognitive engagement.

The results of this study seem to support the current literature well. Several studies measuring cognitive performance with aerobic exercise have shown inconclusive results due to difference in time, duration, intensity, and mode of physical activity. The studies that have shown improvement in cognitive performance during aerobic exercise have seen results only after 30 minutes of exercise (Gabbard \& Barton, 1979; Pontifex, Hillman, Fernhall, Thompson, \& Valentini, 2009). Many of these same studies also only found results when cognitive performance was measured during, rather than after exercise. This may explain why the aerobic exercise group in the current study did not show significant improvements following exercise.

\section{Limitations and Future Research}

Our major limitation within the execution of this study was time. We were limited to the amount of time the students had in their regular P.E. class which was 30 minutes. During this time, the students had to get dressed, find their group condition for the day, participate in the condition for 15 minutes and take their pre and post Stroop tests. Although, we ran on a fairly good schedule through all four days, the stress and 
rush of getting through everything on time may have been a distraction to the students. Along with the time issue, we were not able to allow each student to take their Stroop test in a quiet secluded room where they could focus their attention on the test. Since all of the students were taking the test side by side, several students ended up talking during the test and may have caused unreliable scores. Noise disturbances were most likely a large limitation of the study for the pre and post Stroop tests. The four conditions were executed consistently across all four groups. One researcher was in charge of one condition each day and was responsible for ensuring consistency across groups. Music that was played during the repetitive physical activity condition may have been a means of increasing cognitive engagement. However, music was played for each of the four groups in order to keep conditions consistent. In the future, any environmental conditions that could affect cognitive engagement (music, social communication, etc.) should be controlled for in the aerobic exercise condition. The cognitive engagement in the group games consisted of strategy and social communication among students. Although the same game was played across all four groups, each group consisted of different students, which may have caused different group dynamics, and therefore, a different amount of cognitive engagement. Future studies may want to compare results from the four conditions within the group, as well as across all of the data collected.

The two rest groups consisted of one seated resting group who remained in a seated or laying position for 15 minutes in a quiet room. However, the math/rest group was seated in the same room as the joggers. In this room, there was music playing as well as many other distractions such as the joggers. Furthermore, it was not ensured that all subjects in the math group were seated. In future studies, the two rest groups should 
be controlled in order to ensure they are doing the same type of rest with the exception that the math group was completing the math games while seated rest.

Future research should continue to make real world applications as to how physical education classes can improve students' cognitive performance throughout the school day. Our study showed executive function results immediately before and after conditions. Realistically, we would like to see how students' performance may differ throughout the entire rest of the school day. Another suggestion is to look at time of day. Would students benefit more from taking an early morning physical education class versus a class in the middle of the day? Also, this study focused mainly on one aspect of executive function, inhibition. Other aspects of executive function and cognitive and academic performance should also be looked at. This includes behavior in the classroom and scores on academic achievement tests.

\section{Conclusions}

The results of this study can be very beneficial to advocates looking to sustain physical education in schools. Recently, school boards and administration have been working to cut non-core classes such as P.E. Research suggests that physical activity during the day can be extremely beneficial for cognitive performance, academic achievement, as well as behavior in the classroom. The goal of this study was to examine four conditions, all of which were relatable to what may happen in a real school day for a child. If physical education is replaced with more time in a core subject such as math, our results suggest that we may not actually be benefitting their cognitive performance. Cognitively engaging physical activity such as group games or sports may be the best 
way to enhance cognitive performance throughout the school day. 


\section{CHAPTER II}

\section{REVIEW OF RELATED LITERATURE}

\section{Psychophysiology of Exercise}

Exercise induces physiological changes which may play a role in the improvement of brain health, specifically cognitive functions. The benefits of exercise on brain health have been shown to target the areas of learning and memory, neurodegeneration in the elderly population, and several psychological disorders including depression (Cotman, Bertchold, \& Christie, 2007). In order to understand the ways in which exercise can enhance brain health. There must be a basic understanding of brain structure and how it relates to learning and memory.

The brain is comprised of millions of brain cells called neurons. These neurons communicate everything through the transmissions of various chemicals. These communications dictate every thought and action in the human body. The body has neurotransmitters which carry the messages from one neuron to another neuron. The more often the signal is communicated, the strong the attraction between the neurons becomes (Ratey, 2008). Glutamate and gamma-aminobutyric acid (GABA) are the primary neurotransmitters in charge of the signaling and communication that occurs in the brain. Other important neurotransmitters are serotonin, dopamine, and norepinephrine which are involved in the signaling process to initiate mechanisms in the brain. Finally, 
brain derived neurotrophic factor (BDNF), also called the "miracle grow of the brain," is a key neurotransmitter. It is essential in building, maintaining, and strengthening the cell circuitry in the brain which is a crucial part of the learning process.

The basis of brain health, specifically cognitive functions such as learning and memory, is the brain's ability to develop and connect the neurons associated with the learning process. These connections are made with the help of several growth factors which increase the number of new neurons and their survival (Cotman, Bertchold, \& Christie, 2007). These same changes in the brain that allow for increased memory and learning can be blocked by inflammation in the body. Exercise plays a prime role in regulating the functions in the body that allow changes to occur in order to improve brain health. These changes include the direct upregulation of key growth factors such as insulin-like growth factor-1 (IGF-1), vascular endothelial growth factor (VEGF), and brain-derived neurotrophic factor (BDNF). BDNF is necessary in several areas of brain health including synaptic plasticity, learning, and memory. Berchtold (2005) showed that, following exercise, BDNF production was increased in the hippocampus.

Furthermore, with continued exercise, levels remained high for weeks following the start of the program.

A secondary mechanism caused by exercise to increase brain health is a decrease in inflammation which interferes with growth factor signaling (Cotman, Bertchold, \& Christie, 2007). Synaptic plasticity in the hippocampus, which is primarily useful in spatial learning, is also affected by exercise. Another minor mechanism which supports brain health is exercise's ability to provide the brain with better nutrient access through 
enhanced blood flow and growth of blood vessels in several areas of the brain (Hillman, Erickson, \& Kramer, 2008). Furthermore, exercise has been shown to help neurons grow in spine length, complexity, and density which, in turn, increases the ability to acquire and retain information (Cotman, Bertchold, \& Christie, 2007). Currently, the understanding of the mechanism through which exercise enhances learning and memory is lacking in several areas. More research needs to be done on the duration, intensity, and tasks which will be the most beneficial in improving brain health. Much of the research done on human population has focused on cognitive processes in the frontal lobe of the brain, such as executive function while animal research has mostly focused on hippocampal increases which would affect spatial learning (Cotman, Bertchold, \& Christie, 2007). These two areas need to be expanded to include many different populations and expand the knowledge base to other areas of brain health.

\section{Physical Fitness and Cognition}

Researchers have measured the relationship between physical activity and cognition in several ways. Castelli et al. (2007) found that total fitness was positively related to academic performance in third and fifth graders. Additionally, it was found that aerobic fitness was positively, and body mass index (BMI) negatively, related to total academic achievement, reading scores, and math scores. These findings have let to studies which have shown relationships between physical activity and event-related brain potentials (ERP), which show neuroelectric activity before or after an event (Hillman, Castelli, \& Buck, 2005; Hillman, Snook, \& Jerome, 2003; Pontifex, et al., 2011). Neuroelectric activity is measured in several areas of the scalp and indicates sensory, 
motor, or cognitive events (Friedman, Cycowicz, \& Gaeta, 2001). Specifically, research has looked at the P3 site, which is located in the parietal lobe and has been understood as an indicator of overall arousal within the central nervous system, relating increased P3 amplitude to greater attention allocation and a decreased P3 latency to greater response accuracy. It has been suggested that children with higher fitness levels have greater P3 amplitudes and shorter P3 latency, indicating the ability for greater allocation of attentional resources and quicker, more accurate responses (Hillman, Castelli, \& Buck, 2005). Another prominent study, including 2127 students, tested students in five fitness domains: cardiovascular endurance, abdominal strength, flexibility, upper body strength, and agility. These fitness tests were analyzed with the results from the Massachusetts Comprehensive Assessment System (MCAS) which evaluates students on achievement in Mathematics and English. While the students' fitness levels were more significantly associated with their math scores, the likelihood of them passing both tests increased as the amount of fitness tests passed increased (Math MCAS model $\mathrm{r}^{2}=.24, \mathrm{p}, .0001$ and English MCAS model $\left.\mathrm{r}^{2}=.20, \mathrm{p}=.0004\right)$ (Chomitz, et al., 2009). While these studies aimed to show the important relationship between overall fitness and academic achievement, it is important to consider the direct effect of long term and short term exercise bouts.

Chronic Physical Activity and Cognition

The Trois Rivieres study was an extremely large and significant study that used a school based physical education intervention over a 6 year span to evaluate both short and long term implications of physical activity (Shepard \& Trudeau, 2005). Extensive 
data was collected annually which included physical activity outside of school, bone age, and academic achievement as well as clinical, physiological, anthropometric, and psychomotor evaluations. An important conclusion drawn from the study showed that despite a $14 \%$ reduction in core subjects, the physical activity intervention had a positive effect on academics (Shepard \& Trudeau, 2005). A shorter intervention program of only 10 weeks with low, moderate, and high intensity exercise groups showed that cognitive flexibility increased with increasing intensity in older adults (Masley, Roetzheim, \& Gualtieri, 2009). They showed an increase in cognitive flexibility from 5\% to $30 \%$ from moderate to high intensity exercise. Furthermore, while much of the literature has solely focused on test taking abilities, this study focused on what underlying cognitive functions may be affected by physical activity.

\section{Acute Physical Activity and Cognition}

Perhaps a more influential type of study design used to measure the relationship between physical activity and cognition is an experimental design consisting of acute bouts of exercise with measurements of a cognitive task before, during, and immediately after exercise. Several studies have shown an increase in cognitive function following acute bouts of exercise (Audiffren, Tomporowski, \& Zagrodnik, 2009; McNaughten \& Gabbard, 1993; Pontifex, Hillman, Fernhall, Thompson, \& Valentini, 2009; Hillman, Snook, \& Jerome, 2003). Following acute bouts of moderate-intense treadmill walking in preadolescent children, significant relationships were found between exercise and reading (Hillman, et al., 2009). The authors of this study evaluated test taking skills as well as electroencephalogram (EEG) measurements which revealed the positive effects 
exercise had on cognitive skills. EEG results showed higher P3 amplitudes indicating greater attentional resource allocation. Although there have been profound findings indicating a positive relationship between physical activity and cognition, several studies have also found that physical activity can be debilitating (Weingarten \& John, 1970) tocognitive performance or have no effect (McAdam \& Wang, 1967). Craft (1983) suggested that at optimal levels of arousal, changes in cognitive and behavioral responses may occur, yet results of his study showed no change in cognitive performance among boys with Attention Deficit Hyperactivity Disorder (ADHD). A study which showed the relationship between cognitive function following rest, $70 \%$ intensity, and maximal intensity exercise showed cognitive impairments on a simple reaction time task of recreational athletes only at maximal intensity (McMorris \& Keen, 1994). Possible explanations for the inconclusive results among the current research could be due to multiple methods used such as type of cognitive task performed, intensity of physical activity, duration of activity, age of participant, and presence of cognitive impairment in the subject. These inconsistent conclusions warrant the need for further research involving the time, type, duration, and intensity of exercise and how they relate to specific cognitive processes.

\section{Physical Activity and Executive Function}

Executive function (EF), which is aimed at controlling goal-directed behavior, has been one of the most prominently studied cognitive processes (Best, 2010). EF processes include three components: inhibition, updating of working memory, and shifting. EF is thought to be driven by the neural circuitry in the prefrontal cortex which may help to 
explain the possible effects exercise can have on children (Best, 2010). The different aspects of EF can be measured using several types of tasks. For example, inhibition can be measured using the Erikson flanker task (Eriksen \& Eriksen, 1974). This task required that participants disregard distractor stimuli and focus solely on a target stimulus. They must respond to the stimulus stating the direction of a center arrow that is flanked between congruent or incongruent arrows. Another example of a measure of EF is a task switching test which measures one's ability to shift between different cognitive processes based on the stimulus presented (Best, 2010).

Studies have shown that of different process tasks (speed, visuospatial, controlledprocessing, and executive-control tasks), executive control tasks showed the greatest benefit with increased physical fitness levels (Colcombe \& Kramer, 2003). Furthermore, physical activity at a young age may be imperative for the development of specific executive functions due to progressive changes in the brain (Best, Miller, \& Jones, 2009). Specifically, inhibition may be more susceptible to change than shifting before the age of 5 compared to early adolescence. Most importantly, inhibition is a significant skill for school aged-children in that it can facilitate attentional capacity and behavioral responses. Several studies have supported the role of exercise on aspects of children's executive function, which supports the idea that exercise works to improve mental processes which require more effortful processing (Hillman, Snook, \& Jerome, 2003). Audiffren et al. (2009) had participants perform a 40 minute exercise protocol. The first 5 minutes consisted of cycling at $30 \% \mathrm{VO}_{2}$ max, while the final 35 minutes were performed at $90 \%$ of the participant's ventilator threshold. The cognitive task was performed immediately 
before exercise, 5 times during exercise, and 3 times following exercise. Results showed that this type of steady state exercise protocol had a positive effect on a random number generation task which measured shifting and updating of working memory.

\section{Cognitively Engaging Physical Activity}

There is a newer body of research suggesting that cognitively engaging exercise may act similarly to mental processes that use executive functions by requiring them to create, monitor, and modify specific tasks (Best, 2010). Although the research in this area is somewhat limited, it has been hypothesized that activity with inherent learning and cooperation characteristics (group games) will produce different physiological benefits than repetitive aerobic exercise (treadmill walking, stationary biking, etc.) (Tomporowski, Davis, Miller, \& Naglieri, 2008). For example, while aerobic exercise showed increases in cerebral blood flow, cognitively engaging exercise has shown increases in neural connections (Carey, Bhatt, \& Napgal, 2005). It was suggested that the cognitive skills gained during coordinative physical activity tasks may also translate to EF tasks. There have been few studies that examined the relationship between nonrepetitive exercise and mental performance (Budde, Voelcker-Rehage, PietraßykKendziorra, Ribeiro, \& Tidow, 2008). Much of the research in this area has been limited to non-human subjects which opens the door to examining the relationship between cognitively engaging physical activity and executive function in human subjects. Carey et al. (2005) showed that complex motor movement promotes neural growth in the hippocampus, cerebellum and cerebral cortices in rats to a greater degree than does repetitive motor movement such as walking or running. The complex motor movement 
entailed the rats moving their way through an obstacle course consisting of balance beams, rope bridges, see- saws and other obstacles. Furthermore, studies that have investigated subjects performing physical activity while simultaneously engaging in a learning activity have shown greater cognitive function following activity. Rats that swam through a maze in search of a platform showed higher levels of fibroblast growth factor-2 (FGF-2) compared to a group of rats who swam for the same amount of time but had no cognitive processing (Gómez-Pinilla, 1998).

\section{Summary}

Overall, cognitively engaging physical activity has been defined as activity that requires complex, controlled, and adaptive cognition and movement (Best, 2010). Exercises that fall into this category may include motor movements that require complex coordination, group games requiring strategic behavior, and continuously changing task demands. Specific examples of these tasks could include sport games that require cooperation with other children and constant changes in strategies and behavior as a result of the changing environment. Contextual interference may also play a role in this type of cognitive engagement. This theory suggests that practice situations that involve multiple conditions in a random order provide more interference and therefore may aid in the acquisition and retention of complex skills. Group games and stations, often used in physical education classes, can be developed to contain contextual interference in that, when the situation changes, a child must decide what the next move should be from one scenario to the next. Therefore, contextual interference causes more effortful and elaborate processing, related to executive function processes and greater learning. 
It was the intent of this study to examine the relationship between cognitively engaging physical activity and executive function in youth. Exercise sessions consisted of 20 minutes of either cognitively engaging physical activity or repetitive aerobic exercise at a moderate intensity of $60 \%$ of maximal heart rate. The intensity and duration of exercise for this study were chosen based on previous research which showed moderate intensity for time periods at or longer than 20 minutes is most beneficial in the improvement of executive functions (McNaughten \& Gabbard, 1993; Pontifex, Hillman, Fernhall, Thompson, \& Valentini, 2009; Davranche, Hall, \& McMorris, 2009; Hillman, et al., 2009). Although the research has not been consistent in its methodology, and therefore has had inconsistent results, the methodology of the present study was also designed to be most applicable to a physical education setting. 


\section{REFERENCES}

America, S. (2013). National PE Standards. Retrieved from SHAPE America: http://www.shapeamerica.org/standards/pe/index.cfm

Archibald, S., \& Kerns, K. (1999). Identification and Description of New Tests of Executive Functioning in Children. Child Neuropsychology, 115-129.

Audiffren, M., Tomporowski, P. D., \& Zagrodnik, J. (2009). Acute Aerobic Exercise and Information Processing: Modulation of Executive Control in a Random Number Generation Task. Acta Psychologica, 85-95.

Banich, M. (2009). Executive Function: The Search for an Integrated Account. Association for Psychological Science, 89-94.

Berchtold, N. C., Chinn, G., Kesslak, J. P., \& Cotman, C. W. (2005). Exercise primes a molecular memory for brain-derived neurotrophic factor protein induction in the rat hippocampus. Neuroscience, 853-861.

Best. (2010). Effects of Physical Activity on Children's Executive Function: Contributions of Experimental Research on Aerobic Exercise. Developmental Review, 331-551.

Best, J. R., Miller, P. H., \& Jones, L. L. (2009). Executive Functions After Age 5: Changes and Correlates. National Institute of Healt, 180-200.

Buck, M., Hillman, C., \& Castelli, D. (2008). The Relation of Aerobic Fitness to Stroop Task Performance in Preadolescent Children. Medicine and Science in Sport and Exercise, 166-172.

Budde, H., Voelcker-Rehage, C., Pietraßyk-Kendziorra, S., Ribeiro, P., \& Tidow, G. (2008). Acute Coordinative Exercise Improves Attentional Performance in Adolescents. Neuroscience Letters, 219-223.

Carey, J. R., Bhatt, E., \& Napgal, A. (2005). Neuroplsticity Promoted by Task Complexity. Exercise and Sport Sciences Reviews, 24-31. 
Castelli, D. M., Hillman, C. H., Buck, S. M., \& Erwin, H. E. (2007). Physical Fitness and Academic Achievement in Third- and Fifth-Grade Students. Journal of Sport and Exercise Psychology, 239-252.

Chomitz, V. R., Slining, M. M., McGowan, R. J., Mitchell, S. E., Dawson, G. F., \& Hacker, K. A. (2009). Is There a Relationship Between Physical Activity and Academic Acheivement? Positive Results from Public School Children in Northeastern United States. Journal of School Health, 30-37.

Colcombe, S., \& Kramer, A. (2003). Fitness Effects on the Cognitive Function of Older Adults: A Meta-Analytic Study. Psychological Science, 125-130.

Cotman, C. W., Bertchold, N. C., \& Christie, L.-A. (2007). Exercise Builds Brain Health: Key Roles of Growth Factor Cascades and Inflammation. Trends in Neuroscience, 464-472.

Davranche, K., Hall, B., \& McMorris, T. (2009). Effect of Acute Exercise on Cognitive Control Required During an Eriksen Flanker Task. Journal of Sport and Exercise Psychology, 628-639.

Eriksen, B. A., \& Eriksen, C. W. (1974). Effects of Noise Letters Upon Identification of a Target Letter in a Non-Search Task. Perceptions \& Psychophysics, 143-149.

Friedman, D., Cycowicz, Y., \& Gaeta, H. (2001). The novelty P3: an event-related brain potential (ERP) sign of the brain's evaluation of novelty. Neuroscience and Biobehavioral Reviews, 355-373.

Gabbard, C., \& Barton, J. (1979). Effects of Physical Activity on Mathematical Computation Among Young Children. The Journal of Psychology, 287-288.

Gómez-Pinilla, F. S. (1998). Spatial Learning and Physical Activity Contribute to the Induction of Fibroblast Growth Factor: Neural Substrates for Increased Cognition Associated with Exercise. Neuroscience, 53-61.

Hillman, C. H., Castelli, D. M., \& Buck, S. M. (2005). Aerobic Fitness and Neurocognitive Function in Healthy Preadolescent Children. Medicine and Science in Sports and Exercise Science, 1967-1974.

Hillman, C. H., Pontifex, M. B., Raine, L. B., Castelli, D. M., Hall, E. E., \& Kramer, A. F. (2009). The Effect of Acute Treadmill Walking on Cognitive Control and Academic Acheivement in Preadolescent Children. Neuroscience, 1044-1054. 
Hillman, C. H., Snook, E. M., \& Jerome, G. J. (2003). Acute Cardiovascular Exercise and Executive Control Function. International Journal of Psychophysiology, 307-314.

Hillman, C., Erickson, K., \& Kramer, A. (2008). Be Smart, Exercise your Heart: Exercise Effects on Brain and Cognition. Nature Reviews Neuroscience, 58-65.

Homack, S., \& Riccio, C. (2004). A Meta-Analysis of the Sensitivity and Specificity of the Stroop Color and Word Test with Children. Archives of Clinical Neuropsychology, 725-743.

Lambourne, K., Audiffren, M., \& Tomporowski, P. (2009). Effects of Acute Exercise on Sensory and Executive Processing Tasks. Medicine and Science in Sports and Exercise, 1396-1402.

Lee, S. M., Burgeson, C., Fulton, J., \& Spain, C. (2007). Physical Education and Physical Activity: Results From the School Health Policies and Programs Study 2006. Journal of School Health, 435-463.

Masley, S., Roetzheim, R., \& Gualtieri, T. (2009). Aerobic Exercise Enhances Cognitive Flexibility. Journal of Clinical Psychology in Medical Settings, 186-193.

McAdam, R., \& Wang, Y. (1967). Performance of a Simple Mental Task Following Various Treatments. Research Quarterly, 208-212.

McMorris, T., \& Keen, P. (1994). Effect of Exercise on Simple Reaction Times of Recreational Athletes. Perceptual Motor Skills, 123-130.

McNaughten, D., \& Gabbard, C. (1993). Physical Exertion and Immediate Mental Performance of Sixth-Grade Children. Perceptual and Motor Skills, 1155-1159.

Pontifex, M. B., Hillman, C. H., Fernhall, B., Thompson, K. M., \& Valentini, T. A. (2009). The Effect of Acute Aerobic and Resistance Exercise on Working Memory. Medicine and Science in Sports and Exercise, 927-934.

Pontifex, M., Raine, L., Johnson, C., Chaddock , L., Voss, M., Cohen, N., . . Hillman, C. (2011). Cardiorespiratory Fitness and the Fliexible Modulation of Cognitive Control in Preadolescent Children. Journal of Cognitive Neuroscience, 13321345.

Ratey, J. J. (2008). SPARK: The New Revolutionary Science of Exercise and the Brain. New York, NY: Little, Brown, and Company. 
Shepard, R. J., \& Trudeau, F. (2005). Lesssons Learned from the Trois Rivieres Physical Education Study: A Retrospective. Pediatric Exercise Science, 112-123.

Sibley, B., \& Etnier, J. (2003). The Relationship Between Physical Activity and Cognition in Children: A Meta- Analysis. Pediatric Exercise Science, 243-256.

Tomporowski. (2003). Cognitive and Behavioral Responses to Acute Exercise in Youths: A Review. Pediatric Exercise Science, 348-359.

Tomporowski. (2003). Effects of Acute Bouts of Exercise on Cognition. Acta Psycholgica, 297-324.

Tomporowski, P., Davis, C., Miller, P., \& Naglieri, J. (2008). Exercise and Children's Intelligence, Cognition, and Academic Achievement. Educational Psychological Review, 111-131.

Weingarten, G., \& John, A. (1970). Effects of Physical Exertion on Mental Performance of College Males of Different Physical Fitness Levels. Perceptual and Motor Skills, 371-378. 
APPENDIX

DATA POINTS BY SUBJECT

\begin{tabular}{|c|c|c|c|c|c|c|c|c|}
\hline & CEpre & CEPre & CEPo & CEPo & APre & APre & Аро & Apo \\
\hline & Off & Ave & Off & Ave & Off & Ave & Off & Ave \\
\hline 1 & 11.03 & 11.89 & 10.77 & 12.07 & 10.96 & 10.94 & 9.46 & 11.96 \\
\hline 2 & 12.55 & 13.84 & 11.93 & 11.36 & 10.89 & 16.07 & 11.18 & 14.05 \\
\hline 3 & 12.62 & 12.35 & 13.74 & 12.41 & 11.11 & 12.57 & 10.37 & 12.1 \\
\hline 5 & 12.13 & 15.26 & 11.06 & 13.43 & 10.06 & 12.74 & 11.5 & 12.88 \\
\hline 9 & 9.43 & 10.03 & 9.06 & 10.35 & 8.58 & 9.705 & 9.87 & 10.98 \\
\hline 10 & 9.33 & 10.63 & 8.72 & 10.93 & 9.76 & 10.58 & 8.75 & 9.675 \\
\hline 11 & 11.32 & 10.99 & 9.56 & 9.715 & 9.03 & 9.97 & 9.64 & 8.585 \\
\hline 12 & 11.91 & 12.14 & 9.84 & 11.44 & 11.23 & 10.14 & 9.09 & 10.77 \\
\hline 15 & 11.75 & 12.88 & 11.42 & 10.87 & 10.76 & 11.31 & 10.18 & 12.29 \\
\hline 19 & 13.68 & 13.34 & 11.55 & 11.94 & 11.69 & 13.56 & 13.36 & 13.33 \\
\hline 22 & 9.77 & 12 & 9.76 & 11.47 & 10.63 & 12.63 & 9.48 & 13.91 \\
\hline 24 & 10.27 & 14 & 11.78 & 12.74 & 12.76 & 14.91 & 14.04 & 14.87 \\
\hline 25 & 10.8 & 12.48 & 11.17 & 10.18 & 14.39 & 12.5 & 11.76 & 13.78 \\
\hline
\end{tabular}




\begin{tabular}{|c|c|c|c|c|c|c|c|c|}
\hline 26 & 11.66 & 12.86 & 11.83 & 11.64 & 10.56 & 16.18 & 11.82 & 13.93 \\
\hline 28 & 11.04 & 11.61 & 10.29 & 12.34 & 12.2 & 16.77 & 11.85 & 15.91 \\
\hline 33 & 12.15 & 12.45 & 11.41 & 12.66 & 10.37 & 12.95 & 10.55 & 12.52 \\
\hline 34 & 9.97 & 11.99 & 10.47 & 9.795 & 12.7 & 12.24 & 10.66 & 11.26 \\
\hline 35 & 11.3 & 14.29 & 9.75 & 11.9 & 13.48 & 14.91 & 11.94 & 17.47 \\
\hline 36 & 10.76 & 12.38 & 9.74 & 12.04 & 8.9 & 11.47 & 8.11 & 9.81 \\
\hline 37 & 12.56 & 14.01 & 10.55 & 12.28 & 11.44 & 11.79 & 10.93 & 11.16 \\
\hline 39 & 13.63 & 14.59 & 11.61 & 11.99 & 10.57 & 11 & 10.91 & 11.13 \\
\hline 40 & 12.31 & 11.86 & 12.02 & 12.35 & 9.64 & 10.11 & 10.46 & 10.09 \\
\hline 41 & 14.32 & 14.95 & 13.37 & 12.94 & 12.76 & 12.07 & 10.36 & 12.64 \\
\hline 44 & 11.76 & 12.25 & 11.56 & 13.32 & 11.72 & 13.33 & 12.11 & 12.24 \\
\hline 45 & 12.03 & 12.96 & 11.74 & 10.86 & 10.73 & 11.88 & 11.24 & 12.71 \\
\hline 46 & 11.86 & 13.7 & 9.84 & 12.12 & 10.9 & 12.86 & 9.82 & 11.73 \\
\hline \multirow[t]{3}{*}{47} & 10.52 & 11.65 & 9.3 & 11.27 & 8.73 & 9.385 & 9.23 & 8.82 \\
\hline & MPre & MPre & MPo & MPo & RPre & RPre & RPo & RPo \\
\hline & Off & Ave & Off & Ave & Off & Ave & Off & Ave \\
\hline 1 & 10.25 & 10.81 & 10.64 & 10.88 & 13.43 & 12.29 & 10.62 & 11.72 \\
\hline 2 & 11.32 & 15.01 & 12 & 13.55 & 12.96 & 13.82 & 14.38 & 15.15 \\
\hline 3 & 10.21 & 11.89 & 11.43 & 11.515 & 15.66 & 15.4 & 12.58 & 13.8 \\
\hline 5 & 12.21 & 12.76 & 12.28 & 12.95 & 14.38 & 15.56 & 12.17 & 14.19 \\
\hline 9 & 9.32 & 10.25 & 8.83 & 10.37 & 10.82 & 11.99 & 10.26 & 11.11 \\
\hline 10 & 8.54 & 10.05 & 9.76 & 8.91 & 11.2 & 13.21 & 9.86 & 10.72 \\
\hline
\end{tabular}




\begin{tabular}{|c|c|c|c|c|c|c|c|c|}
\hline 11 & 8.53 & 10.45 & 9.15 & 10.75 & 12.23 & 11.64 & 9.79 & 10.88 \\
\hline 12 & 9.87 & 11.76 & 12.43 & 11.4 & 11.68 & 14.42 & 11.37 & 11.86 \\
\hline 15 & 12.63 & 18.22 & 12.47 & 12.81 & 10.75 & 13.67 & 11.01 & 12.61 \\
\hline 19 & 15.45 & 17.22 & 13.87 & 13.42 & 13.27 & 13.22 & 13.28 & 13.96 \\
\hline 22 & 13.12 & 14.41 & 11.41 & 14.39 & 10.04 & 14.47 & 10.68 & 14.42 \\
\hline 24 & 11.31 & 14.57 & 10.74 & 19.21 & 10.7 & 12.12 & 11.76 & 14.12 \\
\hline 25 & 10.67 & 12.7 & 12.09 & 12.18 & 11.11 & 12.79 & 10.78 & 11.93 \\
\hline 26 & 12.09 & 15.43 & 11.85 & 16.03 & 11.25 & 12.38 & 12.05 & 12.15 \\
\hline 28 & 12.3 & 14.34 & 10.05 & 13.09 & 10.19 & 12.33 & 11.45 & 14.37 \\
\hline 33 & 9.95 & 12.7 & 11.17 & 13.2 & 11.12 & 14.07 & 10.37 & 13.12 \\
\hline 34 & 11.67 & 11.93 & 11.5 & 15.13 & 11.17 & 10.38 & 10.3 & 14.65 \\
\hline 35 & 11.37 & 15.54 & 10.34 & 13.93 & 11.84 & 16.54 & 11.12 & 13.8 \\
\hline 36 & 7.99 & 9.715 & 7.58 & 11.53 & 8.28 & 8.845 & 8.83 & 11.79 \\
\hline 37 & 9.96 & 10.3 & 10.46 & 12.33 & 9.57 & 11.01 & 10.4 & 10.08 \\
\hline 39 & 9.73 & 11.5 & 9.95 & 11.46 & 10 & 11.57 & 12.04 & 9.935 \\
\hline 40 & 10.79 & 11.19 & 9.35 & 10.62 & 9.44 & 10.24 & 9.26 & 11.3 \\
\hline 41 & 11.13 & 12.28 & 10.86 & 12.12 & 11.22 & 11.75 & 11.96 & 11.55 \\
\hline 44 & 10.39 & 10.51 & 11.27 & 11.55 & 9.76 & 10.36 & 10.45 & 10.96 \\
\hline 45 & 10 & 11.86 & 10.8 & 11.16 & 9.75 & 11.97 & 10.94 & 11.03 \\
\hline 46 & 9.89 & 13.2 & 12.29 & 12.47 & 10.36 & 10.59 & 9.39 & 11.86 \\
\hline 47 & 8.95 & 7.95 & 8.07 & 8.14 & 7.85 & 8.865 & 7.31 & 8.55 \\
\hline
\end{tabular}

